\title{
S Wave Velocity Structure in Non-Tectonic SE Asia by Seismogram Analysis of the Earthquakes in Sumatra-Java at TATO Station, Taiwan
}

\author{
Bagus Jaya Santosa \\ Physics Dept., Institut Teknologi Sepuluh Nopember, Kampus ITS, Surabaya \\ Indonesia
}

\section{Introduction}

The Earth's solid mantle is about 2900-km thick and divided into upper and lower mantle (Dziewonski and Anderson, 1981; Kennett, 1991). The lower mantle comprises the region located between the seismically defined discontinuity at $670-\mathrm{km}$ depth and the core-mantle boundary (CMB) at $2900-\mathrm{km}$ depth. It represents $70 \%$ of the volume of the mantle and is still being a controversy in Solid Earth Geophysics, whether the convection is the driving force for the plate tectonics movement. A result of plate tectonic movement is the collision between the earth plates, for example the small India and Asia continents, following the closure of the Thetys Ocean in the Mesozoic time. The collision created the Himalaya and Plato Tibet mountain ranges, also induced an extensive slacking strain in South East Asia and China. Due to the slacking strain, Replumaz et al. (2004), Engdahl et al. (1998) and Grand et al. (1997) have interpreted that the earth structures below the area of South China Sea and South East Asia have a negative anomaly of the P wave velocity. Romanowicz (2003) has also interpreted the $S$ wave velocity beneath South East Asia with negative $S$ anomaly in the upper $410 \mathrm{~km}$ earth mantle and without anomaly in the mantle layers below, refer to fig. 1 .

The western part of Indonesia, especially Java and Sumatra Islands, is an area with a complex tectonic-condition. In this area, the Indian Ocean plate collides with the continental plate. The ridge in the Antarctic sea produces new rocks in lateral direction toward north and south, as a part of the mantle rotation. Since the new produced rock expands laterally, the new rocks push the older plates of ocean in the lateral direction of the ridge field. This pushes the Indian Ocean and Australia Continent to the north, until they collided with the shelf of the South East Asia, and subducted ocean plate under the Eurasia continent. The region in this research lies also in the front area of subduction zone due to collision between the Pacific plate and the Asian plate. The ocean plate moves in an average velocity of $11 \mathrm{~cm} /$ year. The movement is still ongoing, and yield big tectonic earthquakes. It is characterized by the occurrence of earthquakes in this area.

In recent years, tomography is routinely used to process the travel time data from seismic waves, such as International Seismological Center (ISC). This routine especially has become very successful in the mapping on the submergence of the cold lithosphere material into the mantle, along and under the active trench from the edge of the big plates, in three dimensions. 
According to Replumaz et al. (2004), the front area of the subduction field in the continental shelf (Java and Sumatra) experiences a compression and the P wave structure on the upper mantle layers has a positive anomaly. Such velocity structure can be found by inverting the travel-time data of direct $\mathrm{P}$ wave amounting to $\propto 8 \times 10^{6}$, the reflected wave phase Pp amounting to $\propto 0.6 \times 10^{6}$, and biased in the earth core PKP amounting to almost $1 \times 10^{6}$. This amount of data are collected from 300.000 earthquakes in the time interval from $1 / 1 / 1964$ to $31 / 12 / 2000$ (Li et al., 2006); in the same vein, a small amount of the absolute difference of travel times PP-P, PKP-P data diff, is accurately measured by the cross correlation of waveform from the broadband digital waveform data (Grand et al., 1997). Fig. 1 presents the interpreted earth structure beneath SE Asia using the P travel time (Romanowicz, 2003).

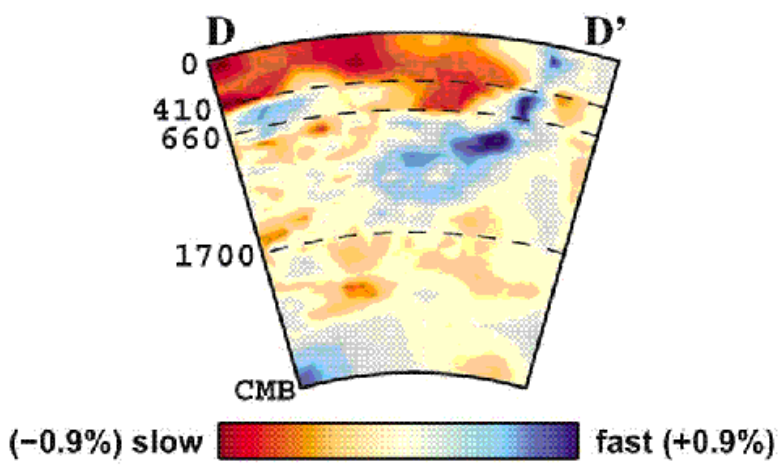

Fig. 1. Depth cross section DD' in front area of subduction zone area in Java-Sumatra, as revealed by P travel-time tomography using ISC data (Romanowicz, 2003)

I present the analysis result of the $S$ wave, the Love and Rayleigh surface waves, to evaluate the nature of mantle below South East Asia and South China Sea, by analyzing the seismogram from the earthquakes that occurred on the surface of Java-Sumatra subduction zone that were recorded in the observatory station TATO, Taiwan. The objective of this research is to understand the $S$ wave velocity structure beneath SE Asia using seismogram fitting method on the $S$ and surface waves, in time domain and three components simultaneously.

The synthetic seismogram is calculated using GEMINI Program (Dalkolmo, 1993; Friederich and Dalkolmo, 1995), which is equivalent with Normal Mode method, but the difference is in the independent variable used. GEMINI uses complex frequency, instead of real frequency as in the Normal Mode.

\section{Data}

Table 1 presents the epicenter location of the analyzed earthquakes. The earthquake set consists of three earthquakes in North Sumatra Coast, five earthquakes in South Sumatra and Sunda Strait, and two earthquakes in South Java.

Fig. 2 indicates wave propagation from the earthquake hypocenters in the subduction zone to the TATO station. The waves pass through the western side of Southeast Asia that lies on the 


\begin{tabular}{|c|c|c|c|}
\hline $\mathrm{No}$ & Earthquake Code & Latitude & Longitude \\
\hline 1 & B031501B & 8.66 & 94.01 \\
\hline 2 & C103194B & 3.03 & 96.27 \\
\hline 3 & C110895A & 1.44 & 95.59 \\
\hline 4 & C090100C & 1.44 & 96.59 \\
\hline 5 & C011601D & -4.02 & 101.78 \\
\hline 6 & B020893B & -4.86 & 101.96 \\
\hline 7 & B082400C & -6.03 & 102.69 \\
\hline 8 & B020399B & -6.19 & 104.22 \\
\hline 9 & C011502D & -6.31 & 105.21 \\
\hline 10 & C060394F & -10.49 & 112.87 \\
\hline 11 & B061594F & -10.28 & 113.85 \\
\hline
\end{tabular}

Table 1. Codes and epicenter location of the earthquakes in Sumatra-Java that are analyzed in TATO observatory station

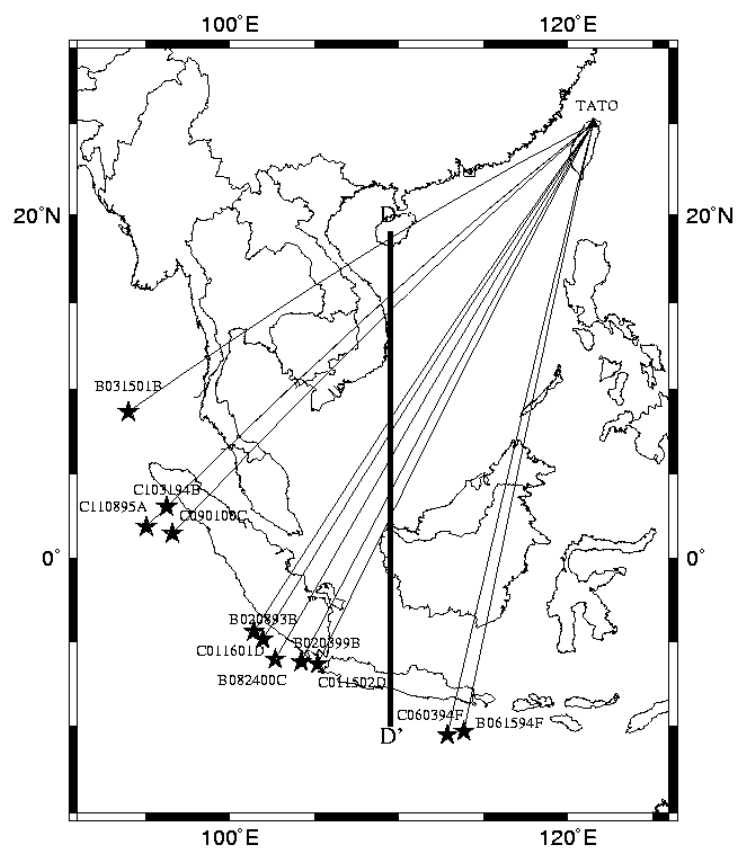

Fig. 2. Vertical projection of ray paths from epicenter to observatory station in TATO and line cross section $\mathrm{DD}^{\prime}$

front side of the Philippines subduction zone. The wave propagating medium between the earthquakes epicenter to TATO station traverses this non-tectonic area, which experiences a 
slacking strain as a result of the convergence between the India Sub-continent and the Eurasia Sub-continent plates.

\section{Seismogram analysis and discussion}

\subsection{Seismogram analysis and fitting}

Figure 3 presents the seismogram fitting of the B031501B earthquake, Nicobar archipelago that was recorded in TATO station. We can see that the PREMAN (the vertical anisotropic version of PREM (Dziewonski and Anderson, 1981)) global earth model predicts synthetic Love waveform that arrives rather earlier than the measured Love waveform, and the observation on the synthetic wave Rayleigh also shows earlier arrival time than the measured one. The corrected earth model gives a good synthetic seismogram on the Love and Rayleigh surface waves and also the SV and SH body waves. It is obtained by changing the gradient $\beta_{h}$ in the upper mantle layers into positive and by giving a negative correction on the zero order polynomial coefficients that describe the $\beta$ structure on the mantle layers up to $730 \mathrm{~km}$ depth.

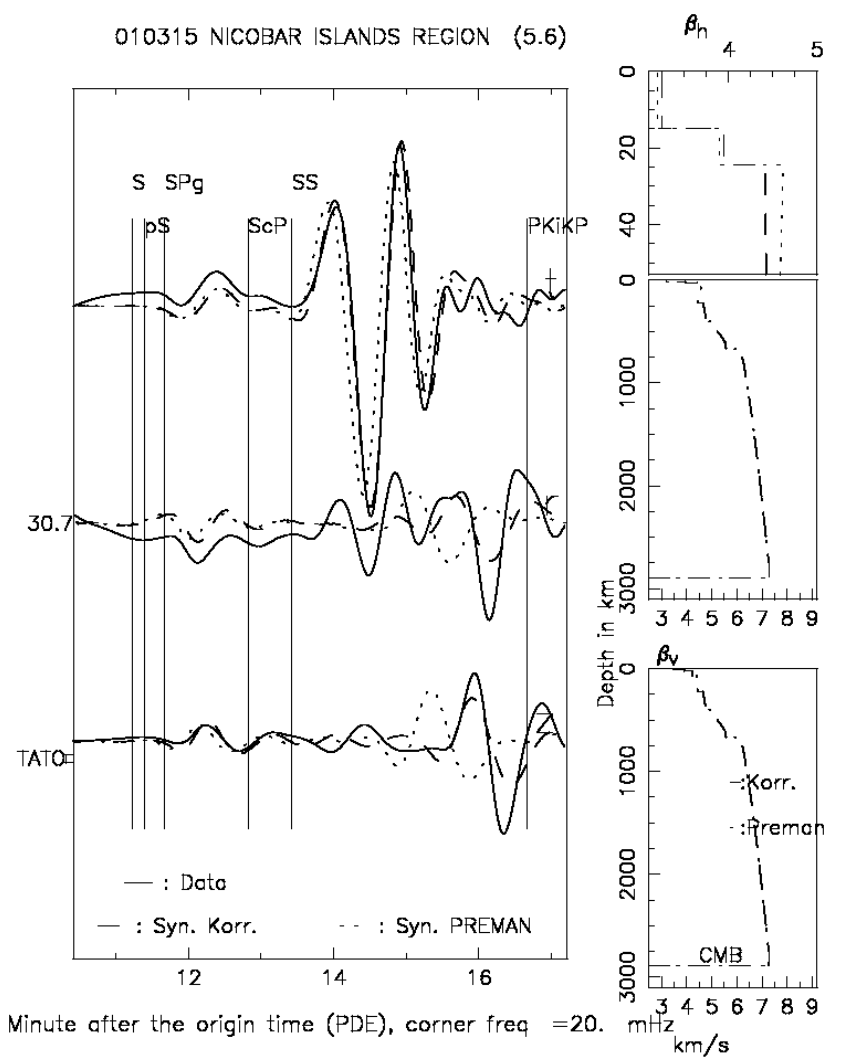

Fig. 3. The seismogram fitting of Nicobar B031501B earthquake in TATO.

Figure 4 indicates an illustration about the seismogram fitting of the C103194B earthquake, North Sumatra at TATO station. We see in the spheroidal components ( $\mathrm{r}$ and $\mathrm{z}$ components), 
941031 NORTHERN SUMATERA

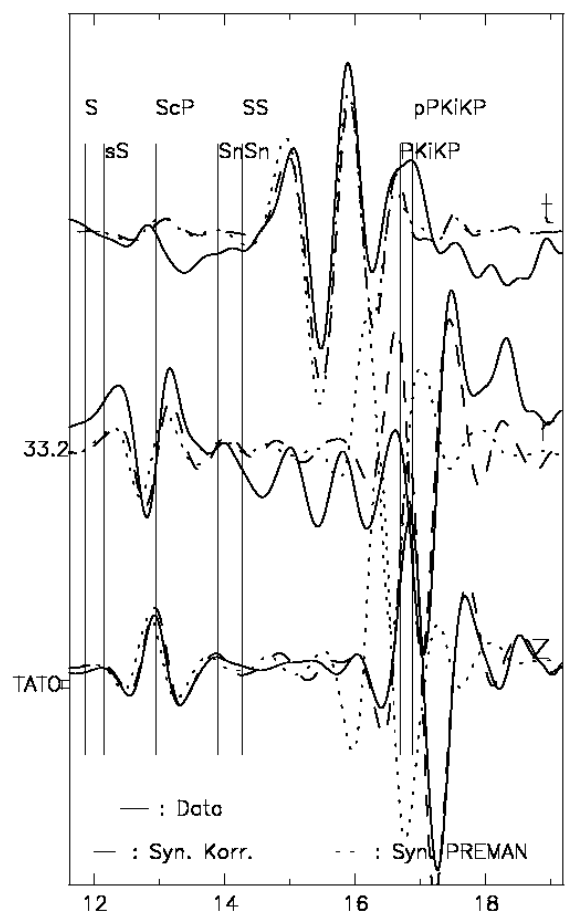

Minute after the origin time (PDE), corner freq $=20$
(5.6)

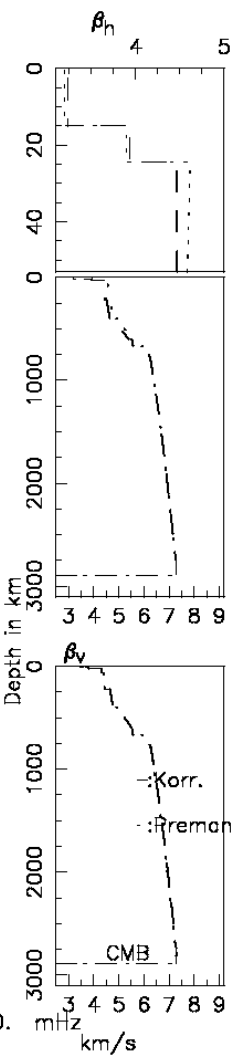

Fig. 4. The seismogram fitting of North Sumatra C103194B earthquake in TATO.

that the synthetic seismogram constructed from the PREMAN earth model arrives further earlier in the Rayleigh wave and arrives less early for S wave. It indicates that a great negative correction should be imposed on $\beta_{v}$ in the upper mantle layers and also weaker negative correction on the mantle layers below until $730 \mathrm{~km}$ depth.

Figure 5 presents the seismogram analysis of the C110895A earthquake, the North Sumatra oceanic trench in TATO station. We can see that the synthetic seismogram from PREMAN on the Rayleigh arrives earlier than its measured waveform, while the Love waveform arrives a bit earlier. The synthetic seismogram of the corrected earth model agrees well with the measured data for Rayleigh wave, and also for the SV wave. In the $t$ component, the Love waveform agrees better with the seismogram constructed from corrected model.

The seismogram analysis and fitting of the C090100C earthquake, North Sumatra trench, can be seen in Fig. 6. Since the data quality on $t$ component is poor, the analysis is carried out just on the Rayleigh and SV wave in the $\mathrm{r}$ and $\mathrm{z}$ components. The zeroth order coefficients of $\beta_{v}$ velocity function requires a big negative correction on the upper mantle layers, and smaller negative correction on the mantle layers below. 
951108 OFF W COAST OF NORTHERN (6.1)

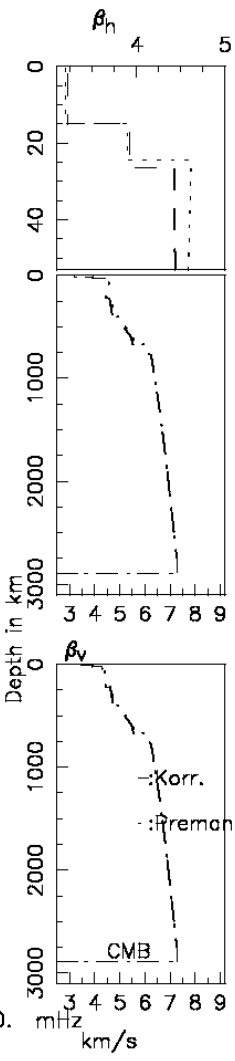
htb]

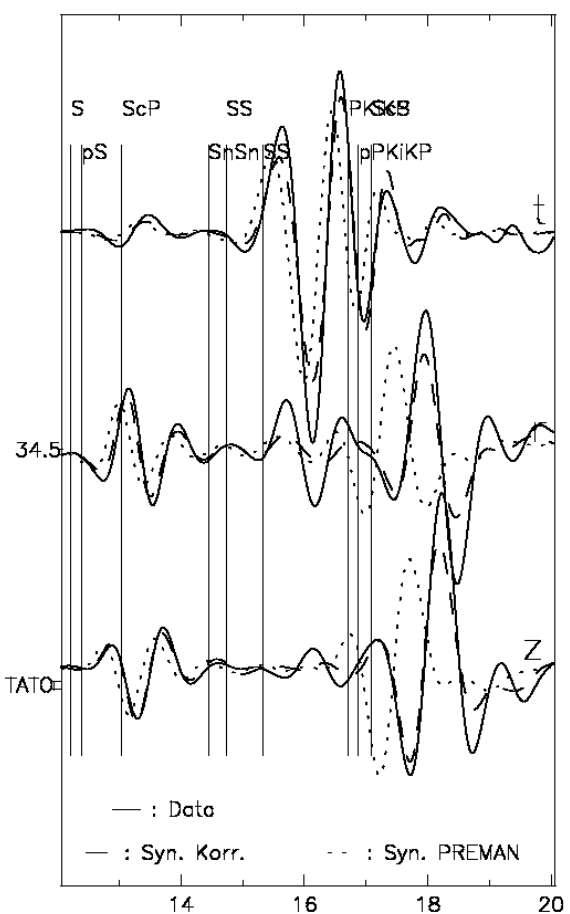

Minute after the origin time (PDE), corner freq $=20$

$\mathrm{km} / \mathrm{s}$

Fig. 5. The seismogram fitting of North Sumatra C110895A earthquake in TATO.

The seismogram analysis and fitting of the C011601D earthquake, South Sumatra trench, can be seen in Figure 7. The analysis is carried out on the Rayleigh and SV wave in the $r$ and $\mathrm{z}$ components, and Love wave in the $\mathrm{t}$ component. The difference between the measured Rayleigh and the corresponding synthetic waveform is too big. So the negative correction on zero order coefficients of $\beta_{v}$ velocity function is imposed on the mantle layers, with a big negative correction on the upper mantle layers, while the mantle layers below require a weak negative correction.

Figure 8 presents a seismogram analysis and explanation of the B020893B earthquake that occurred in the South Sumatra trench, where the seismogram was recorded in TATO station. We can see that the amplitude of the SV synthetic wave approaches the amplitude of the SV measured wave. But the amplitude of the synthetic Rayleigh wave is much higher than that of the measured Rayleigh. Therefore, a fitting is carried out in order to find a good fitting on the travel time of the maximum Rayleigh amplitude. The discrepancies in wave amplitude height were resulted from inaccuracy in the solution determination of the CMT earthquake (Dreger, 2002). 


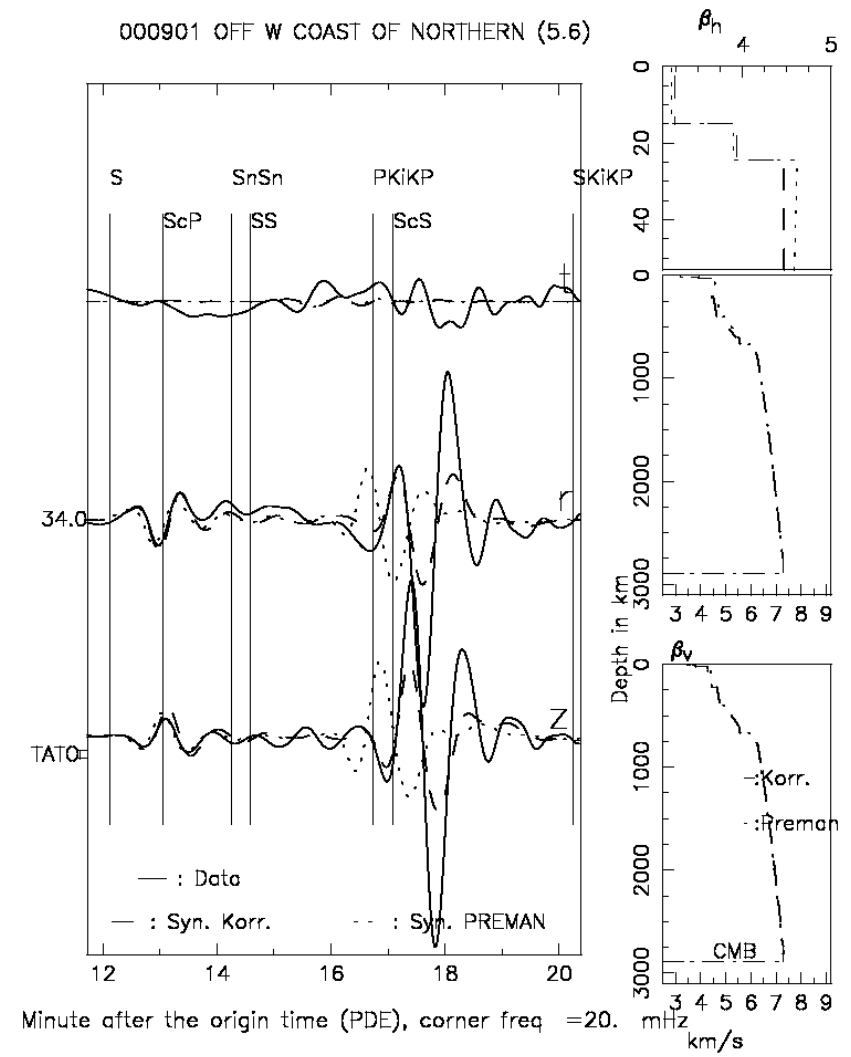

Fig. 6. The seismogram fitting of North Sumatra C090100C earthquake in TATO.

Figure 9 presents the seismogram analysis of the B082400C earthquake, South Sumatra Trench that was recorded in TATO station. The quality of data on $t$ component is poor, so that the seismogram fitting is done on Rayleigh wave in two $\mathrm{r}$ and $\mathrm{z}$ components. We can see that a strong negative correction on $\beta_{v}$ should be imposed at the upper mantle layers to obtain a fitting on the Rayleigh wave, whereas the mantle layers below do not need to be corrected, because the SV wave has also been well simulated.

The analysis and fitting of the B020399B seismogram that occurred in Sunda Strait which is recorded in TATO station, is illustrated in Figure 10. The synthetic seismogram that constructed from the PREMAN earth model has a different Rayleigh waveform from the measured waveform. They arrive earlier, and with the different amplitude heights distribution in the first and second maximums of Rayleigh wave; whereas the measured Rayleigh has a smaller decaying trend. The corrected earth model provides a better fitting on the pattern distribution of the maximums of the Rayleigh wave and the arrival time that approaches the measured Rayleigh wave. It is obtained by imposing a correction on $\beta_{v}$, and by using the positive $\beta_{h}$ gradient on the upper mantle layers. 


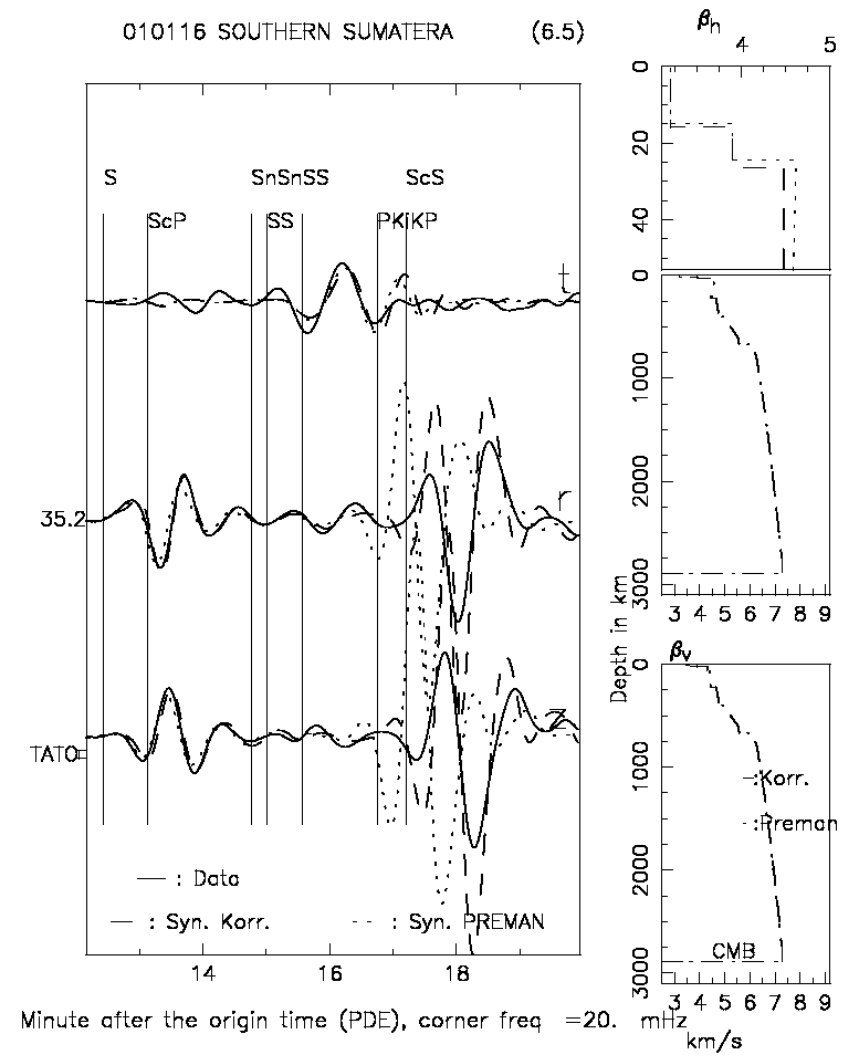

Fig. 7. The seismogram fitting of North Sumatra C011601D earthquake in TATO.

Figure 11 presents the seismogram analysis and fitting of the C011502D earthquake, Sunda strait, which is recorded in TATO station. We can see that the corrected earth model provides a synthetic seismogram that resembles more closely to the measured seismogram, than the synthetic seismogram that is constructed from the PREMAN earth model. The main negative correction is imposed on $\beta_{v}$ on the upper mantle layers.

Figure 12 presents seismogram analysis and comparison of the C060394F earthquake, the south Java trench that occurred on June 3rd, 1994. We can see that the fitting of the synthetic seismogram calculated from the corrected earth-model approaches the measured seismogram well, both on the beginning of the Love wave (constituting the SS wave), the Rayleigh wave and the SV and SH. The big amplitude at the end part of the Love wave cannot be simulated by both synthetic waves.

Figure 13 indicates a comparison of the measured seismogram and the synthetic one from a B061594F earthquake that occurred in the South Java trench in June 15th 1994, twelve days after the earthquake that is presented in Figure 11. We can see the deviations of the synthetic seismogram constructed from the PREMAN earth model against the measured seismogram. The corrected earth model provides a synthetic seismogram that approaches 


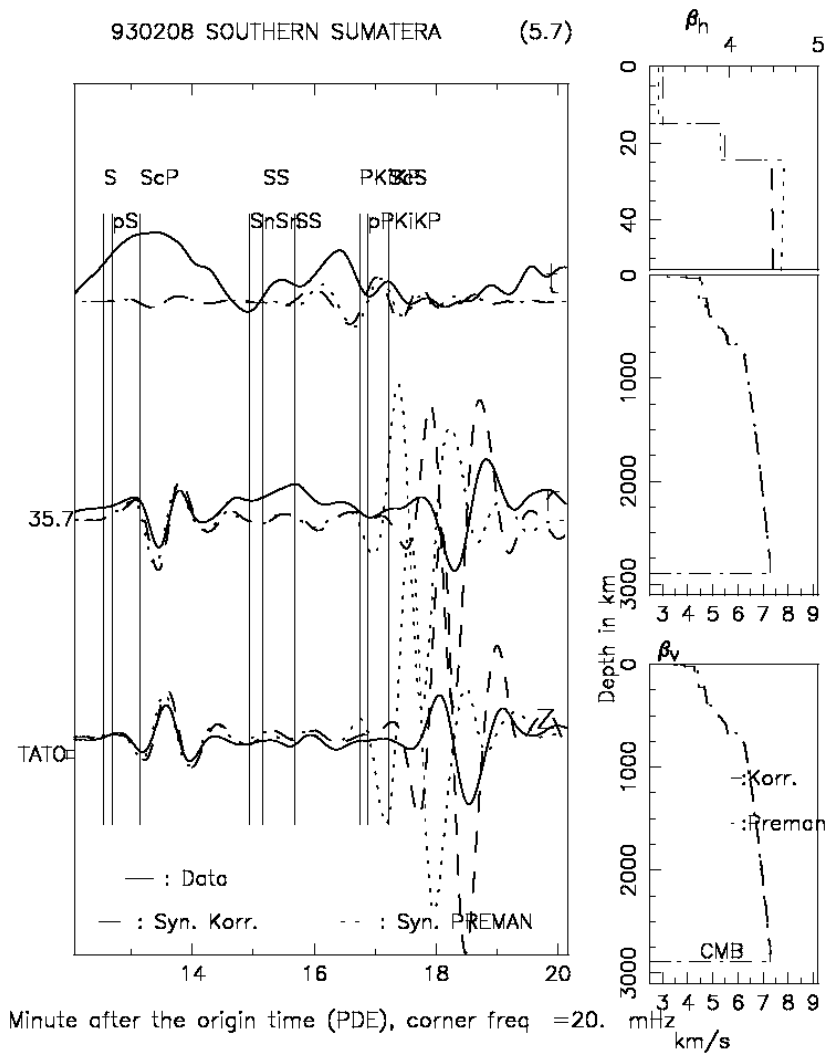

Fig. 8. The seismogram fitting of South Sumatra B020893B earthquake in TATO.

the main oscillations in Love and Rayleigh surface waves, and fitting is also achieved on the SV wave.

\subsection{Discussion}

The PREMAN earth model is presented with the vertical anisotropy only in the upper mantle layers. Following this research, we can see that all of the earthquakes analyzed indicate the earlier arrival time on the synthetic surface Rayleigh wave from the PREMAN model. This requires a negative correction on the velocity structure $\beta_{v}$, with a significant magnitude, where it indicates a greater vertical anisotropy than the one stated in the PREMAN earth model. To obtain a fitting on the $\mathrm{S}$ wave (SV and $\mathrm{SH}$ ) on the seismograms of some earthquakes, we need a negative correction with a weaker magnitude on the mantle layers until $730 \mathrm{~km}$ depth. It indicates that the vertical nature of anisotropy also occurs in the mantle layer below the upper mantle. This anisotropy nature has not been used in the seismogram research that is based on the travel-time data. Result of this research complements the result from (Replumaz et al., 2004) and (Romanowicz, 2003) about the $S$ wave velocity structure under South East Asia and South China Sea. 
ODOB24 SOUTHWEST OF SUMATERA

(5.7)

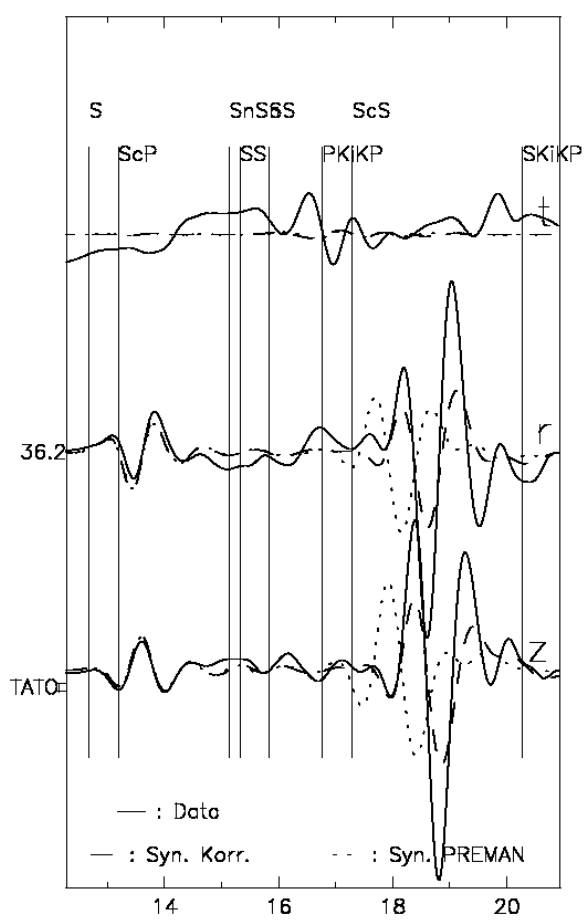

Minute after the origin time (PDE), corner freq $=20$.

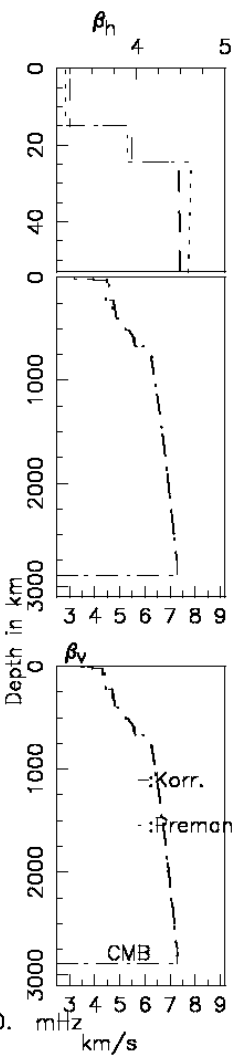

Fig. 9. The seismogram fitting of South Sumatra B082400C earthquake in TATO.

The epicenters of three earthquakes in North Sumatra coast lie close to each other, five earthquakes in Sunda Strait and South Sumatra also lie close each other, and two earthquakes in South Java Coast, indicate that the earth model beneath South-East Asia has S wave velocity anomaly which is big negative in upper mantle layers, and small negative in mantle layers till $730 \mathrm{~km}$ depth.

The CMT solution determination of earthquakes, that is done with CMT Routine (Dreger, 2002), relies on the isotropic earth model, and known as the 1066B earth model, in which the Green functions are calculated for various depths of the earthquake sources; and then reconstruction of the synthetic seismogram. The software in this package performs a time domain inversion of three-component seismic data for the seismic moment tensor. Source depth is found iteratively by finding the solution that yields the largest variance reduction between the observed and synthetic seismogram and the magnitude of the earthquake is obtained by Monte Carlo Method. The TDMT_invc (Dreger, 2002) uses still isotropic earth model to determine the magnitude and moment tensors of the earthquake, which after this research we found that the earth model should be described with an anisotropic earth model. 


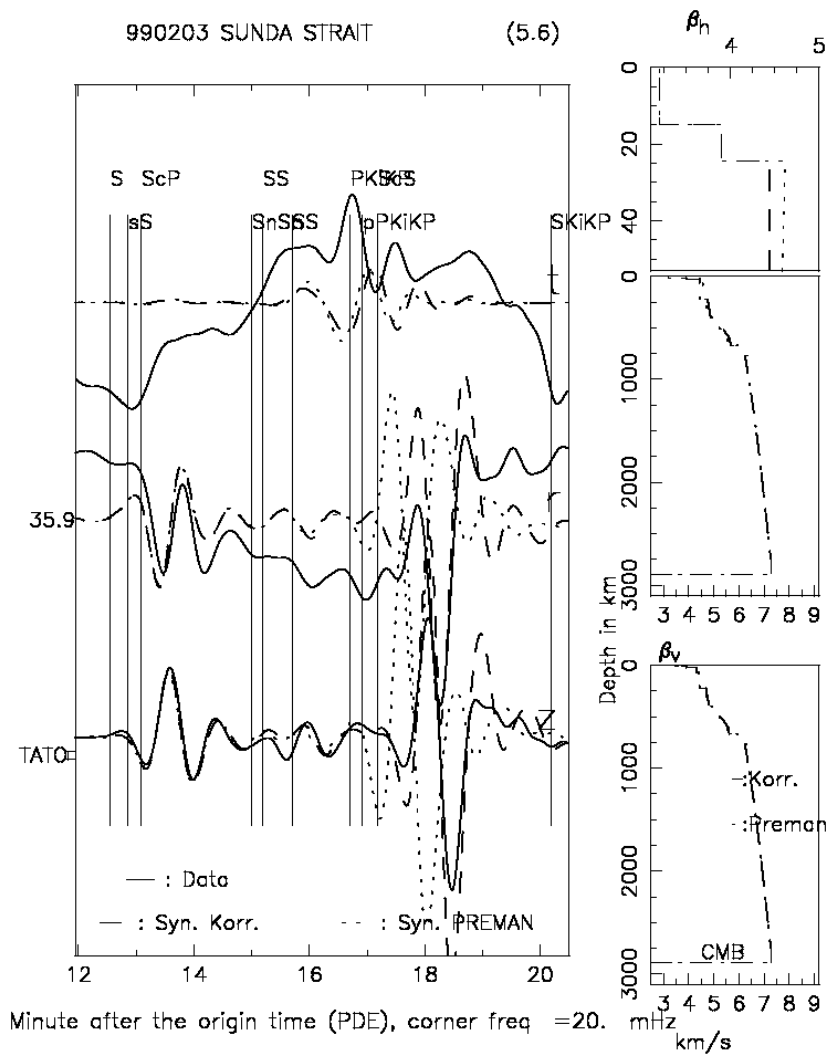

Fig. 10. The seismogram fitting of Sunda Strait B020399B earthquake in TATO.

Table 2 presents an example of the $S$ wave velocity in various earth mantle layers, in which the PREMAN earth model was compared with the corrected model of the earth between the earthquake hypocenter C031995G and the TATO observatory station. We can see that the values of $\beta_{v}$ zero order coefficients in the upper mantle have stronger negative terms than the PREMAN model. The $S$ wave velocity structure of the other earthquakes can be seen by noticing the inset that contains the velocity structure of the $S$ wave that lies on the right side of Fig.3 through Fig.13. We can see that the vertical anisotropy ( $\eta$ value) occurs in all of the mantle layers, not only in the upper mantle layer as stated in the PREMAN earth model. We notice further by comparing the second and third columns with the fifth and the sixth column, respectively, that the zero order coefficients of the $S$ wave velocity generally has a negative anomaly in all layers of the mantle. 


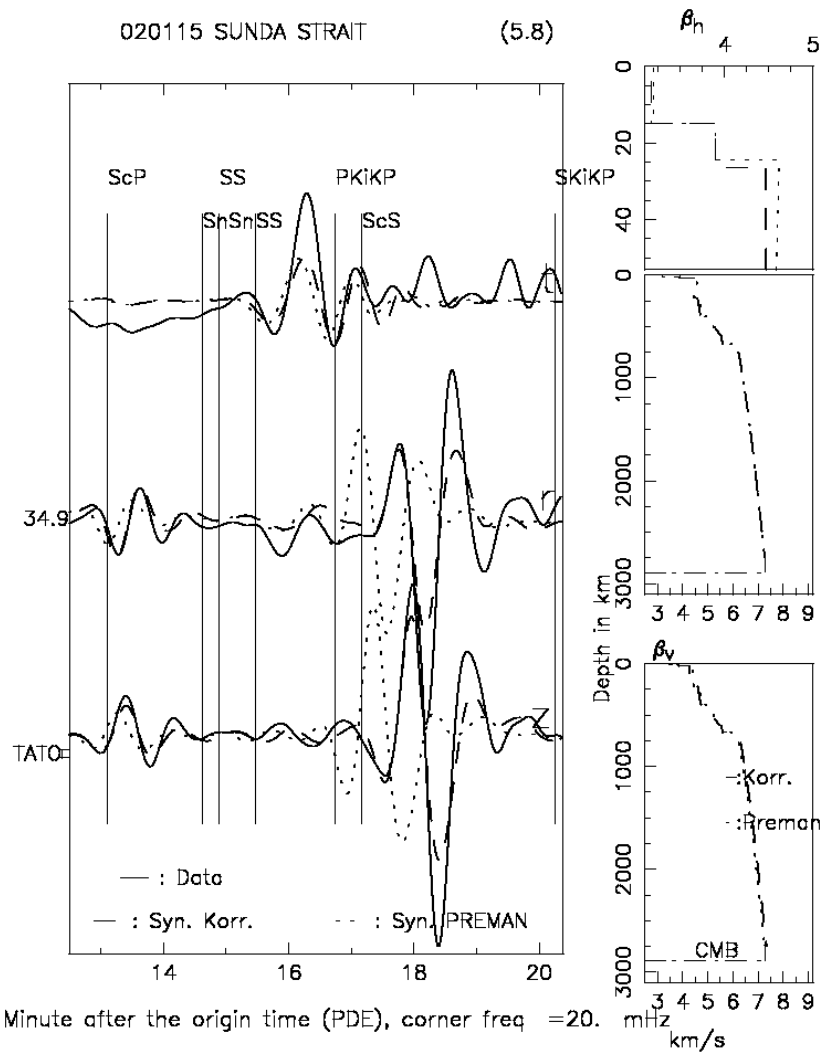

Fig. 11. The seismogram fitting of Sunda Strait C011502D earthquake in TATO. 


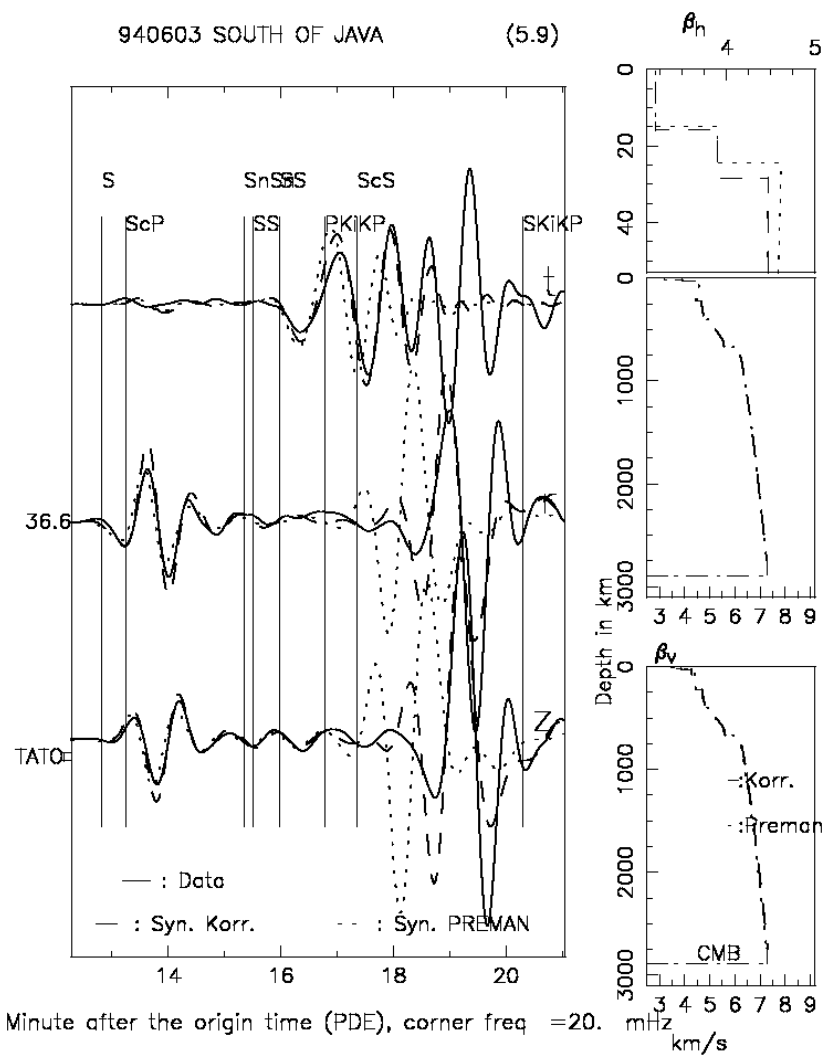

Fig. 12. The seismogram fitting of South Java trench C060394F earthquake in TATO. 

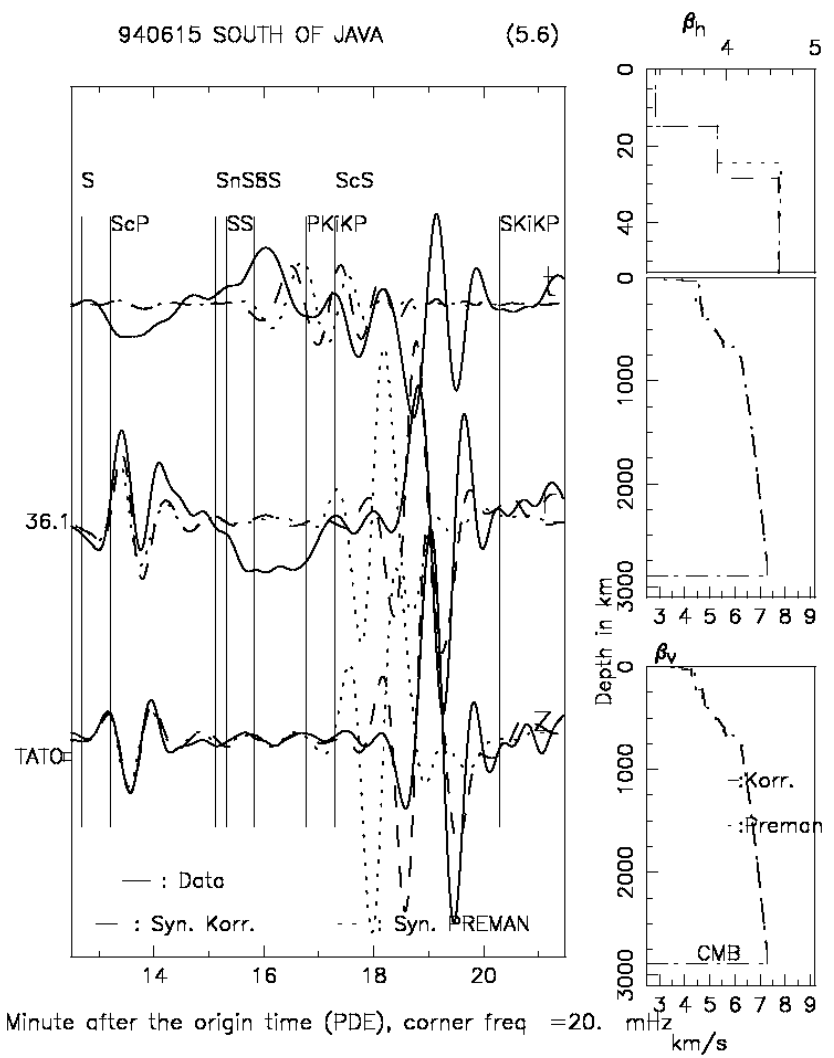

Fig. 13. The seismogram fitting of South Java trench B061594F earthquake in TATO. 


\begin{tabular}{|c|c|c|c|c|c|c|}
\hline \multicolumn{4}{|c|}{ PREMAN } & \multicolumn{3}{|c|}{ B020893B-TATO } \\
\hline $\begin{array}{c}\text { Radius } \\
\mathrm{km}\end{array}$ & $\begin{array}{c}\beta_{v} \\
(\mathrm{~km} / \mathrm{s})\end{array}$ & $\begin{array}{c}\beta_{h} \\
(\mathrm{~km} / \mathrm{s})\end{array}$ & $\eta$ & $\begin{array}{c}\beta_{v} \\
(\mathrm{~km} / \mathrm{s})\end{array}$ & $\begin{array}{c}\beta_{h} \\
(\mathrm{~km} / \mathrm{s})\end{array}$ & $\eta$ \\
\hline 3480.0 & 6.9254 & 6.9254 & 1.0 & 6.9454 & 6.9254 & 0.9971 \\
\hline 3630.0 & 11.1671 & 11.1671 & 1.0 & 11.1871 & 11.1671 & 0.9982 \\
\hline 5600.0 & 22.3459 & 22.3459 & 1.0 & 22.3559 & 22.3959 & 1.0017 \\
\hline 5701. & 9.9839 & 9.9839 & 1.0 & 10.0039 & 10.0039 & 1.0000 \\
\hline 5771.0 & 22.3512 & 22.3512 & 1.0 & 22.3912 & 22.4412 & 1.0022 \\
\hline 5971.0 & 8.9496 & 8.9496 & 1.0 & 8.9696 & 9.0496 & 1.0089 \\
\hline 6151.0 & 5.8582 & -1.0839 & 3.3687 & 5.7382 & 5.9009 & 1.0283 \\
\hline gradient & -1.4678 & 5.7176 & & -1.4678 & -1.4278 & \\
\hline 6291.0 .0 & 5.8582 & -1.0839 & 3.3687 & 5.7382 & 5.9009 & 1.0283 \\
\hline gradient & -1.4678 & 5.7176 & & -1.4678 & -1.4278 & \\
\hline 6346.6 & 3.9000 & 3.9000 & 1.0 & 3.8900 & 3.9400 & 1.0129 \\
\hline 6356.0 & 3.2000 & 3.2000 & 1.0 & 3.1900 & 3.2400 & 1.0157 \\
\hline 6371.0 & & & & & & \\
\hline
\end{tabular}

Table 2. The velocity structure of $S$ wave between the PREMAN earth model and the corrected model of the earth for the B020893B earthquake in the TATO station; the zero-order coefficients of $S$ wave and the velocity gradient of $\beta_{h}$ on the upper mantle $(61516346.6 \mathrm{~km})$ are also shown

\section{Conclusion}

The $S$ wave velocity of the region ahead of the subduction field and non-tectonic areas beneath South-East Asia have been investigated using seismogram analysis of the earthquakes that occurred on the subduction plane of Java - Sumatra that was recorded in TATO station, Taiwan, in the time domain and the three Cartesian components simultaneously. The data set used in this research contains all information in seismograms, unlike the travel time data set, which is just a small part of the information contained in the seismogram.

The synthetic seismogram is calculated using the GEMINI method which is equivalent to the Normal Mode. To simplify the waveform, the seismogram is low-pass-filtered, with a corner frequency of $20 \mathrm{mHz}$

The seismogram comparison indicates that the synthetic seismogram from Java-Sumatra earthquake that was recorded in TATO and calculated from the PREMAN earth model, indicates the earlier arrival-times than the measured wave on the same phase, on both Love and Rayleigh waves. A correction is imposed by changing the gradient $\beta_{h}$ into positive, and the zero-order coefficients of $\beta_{v}$ and $\beta_{h}$ on the polynomial function of the $S$ wave velocity, in every mantle layer. The negative correction is primary on the $\beta_{v}$. Fitting is obtained on the Rayleigh wave, a correction is also tried on the S and SS body waves. It indicates that the vertical anisotropy is stronger than the one included in the PREMAN earth model and also occurs in the mantle-layers under the upper mantle.

A big negative correction occurs in the upper layer of mantle. It suggests that the part of mantle that experiences a straining due to a tectonic process where the Indian continent impact the Asia Continent, has a negative velocity anomaly on the upper mantle layer and the layers below. 


\section{References}

Dalkolmo, J., (1993). Synthetische Seismogramme für eine sphärisch symmetrische, nichtrotierend Erde durch direkte Berechnung der Greenschen Funktion, Diplomarbeit, Inst. für Geophys., Uni. Stuttgart.

Dreger, D.S., (2002). Time-Domain Moment Tensor INVerse Code (TDMT_INVC), The Berkeley Seismological Laboratory (BSL), report number 8511.

Dziewonski, A.M. and Anderson, D.L. (1981). Preliminary reference Earth model, Phys. of the Earth and Plan. Int., Vol. 25, 297 - 356.

Engdahl, E.R., Van Der Hilst, R.D., Buland, R.P., (1998). Global teleseismic earthquake relocation with improved travel times and procedures for depth determination, Bull. Seism. Soc. Am., Vol. 88, 722 - 743.

Friederich, W. and Dalkolmo, J., (1995). Complete synthetic seismograms for a spherically symmetric earth by a numerical computation of the green's function in the frequency domain, Geophys. J. Int., Vol. 122, 537 - 550.

Grand, S.P., Van Der Hilst, R.D., Widiyantoro, S., (1997). Global seismic tomography; a snapshot of convection in the Earth, GSA Today, Vol. 7, 1 - 7.

Kennett, B.L.N., (1991). IASPEI 1991, Seismological Tables, Research School of Earths Sciences, Australian National University.

Li, C., Van der Hilst, R.D., and Toksoz, N.M., (2006). Constraining spatial variations in P-wave velocity in the upper mantle beneath SE Asia, Phys. of the Earth and Plan. Int., Vol. $154,180-195$.

Romanowicz, B., (2003). 3D Structures of the Earth Lower Mantle, C.R. Geoscience, Vol. 335, $23-35$

Replumaz, A, Kárason, H, van der Hilst, R. D., Besse, J. and Tapponnier, P., (2004). 4-D evolution of SE Asia's mantle from geological reconstructions and seismic tomography, Earth and Planetary Science Letters, Vol. 221, 103 - 115 


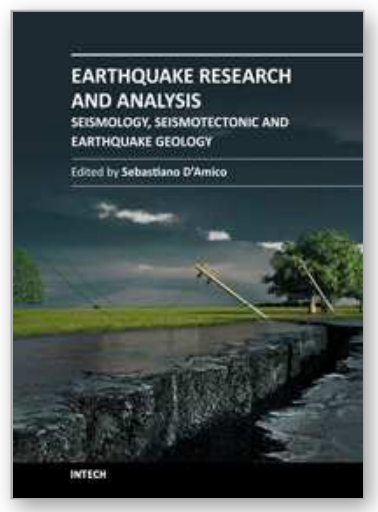

\section{Earthquake Research and Analysis - Seismology, Seismotectonic and Earthquake Geology}

Edited by Dr Sebastiano D'Amico

ISBN 978-953-307-991-2

Hard cover, 370 pages

Publisher InTech

Published online 08, February, 2012

Published in print edition February, 2012

This book is devoted to different aspects of earthquake research. Depending on their magnitude and the placement of the hypocenter, earthquakes have the potential to be very destructive. Given that they can cause significant losses and deaths, it is really important to understand the process and the physics of this phenomenon. This book does not focus on a unique problem in earthquake processes, but spans studies on historical earthquakes and seismology in different tectonic environments, to more applied studies on earthquake geology.

\section{How to reference}

In order to correctly reference this scholarly work, feel free to copy and paste the following:

Bagus Jaya Santosa (2012). S Wave Velocity Structure in Non-Tectonic SE Asia by Seismogram Analysis of the Earthquakes in Sumatra-Java at TATO Station, Taiwan, Earthquake Research and Analysis - Seismology, Seismotectonic and Earthquake Geology, Dr Sebastiano D'Amico (Ed.), ISBN: 978-953-307-991-2, InTech, Available from: http://www.intechopen.com/books/earthquake-research-and-analysis-seismologyseismotectonic-and-earthquake-geology/s-wave-velocity-structure-in-non-tectonic-se-asia-by-seismogramanalysis-of-the-earthquakes-in-sumat

\section{INTECH}

open science | open minds

\section{InTech Europe}

University Campus STeP Ri

Slavka Krautzeka 83/A

51000 Rijeka, Croatia

Phone: +385 (51) 770447

Fax: +385 (51) 686166

www.intechopen.com

\section{InTech China}

Unit 405, Office Block, Hotel Equatorial Shanghai

No.65, Yan An Road (West), Shanghai, 200040, China 中国上海市延安西路65号上海国际贵都大饭店办公楼 405 单元

Phone: +86-21-62489820

Fax: +86-21-62489821 
(C) 2012 The Author(s). Licensee IntechOpen. This is an open access article distributed under the terms of the Creative Commons Attribution 3.0 License, which permits unrestricted use, distribution, and reproduction in any medium, provided the original work is properly cited. 